Article

\title{
Polymorphisms of Proinflammatory Cytokines in Relation to APOE Epsilon 4 and Risk of Alzheimer's Disease in the Lithuanian Population
}

\author{
Greta Pšemeneckienè *, Kęstutis Petrikonis and Daiva Rastenytė \\ Department of Neurology, Medical Academy, Lithuanian University of Health Sciences, LT-50161 Kaunas, \\ Lithuania; kestutis.petrikonis@lsmuni.lt (K.P.); daiva.rastenyte@lsmuni.lt (D.R.) \\ * Correspondence: greta.psemeneckiene@lsmuni.lt; Tel.: +370-687-92311
}

Received: 8 July 2019; Accepted: 9 October 2019; Published: 15 October 2019

\begin{abstract}
Background and objective: Neuroinflammation is one of the pathological pathways of Alzheimer's disease (AD), mediating the progression of neurodegeneration. Polymorphisms of proinflammatory cytokines have been linked to increased AD risk. Identification of certain combinations of polymorphisms could help predict disease in its preclinical stage. The aim of the study was to evaluate differences in the prevalence of TNF $\alpha-850 \mathrm{~T}$ (rs1799724), IL1A -889T (rs1800587), and IL6 -174C (rs1800795, Intron type) polymorphisms between AD patients and healthy controls (HC) and determine the impact of these SNPs in combination with the APOE\&4 allele on AD risk. Materials and Methods: The study population is comprised of 107 patients with sporadic $\mathrm{AD}$ (AD group) and age- and gender-matched 110 persons without impaired cognitive functions (control group). TNF $\alpha-850 \mathrm{C}>\mathrm{T}$ polymorphism was revealed by a PCR and restriction fragment length polymorphism (RFLP) method. Real time PCR was used for IL1A and IL6 SNP genotyping. APOE $\varepsilon$ genotyping was done via hybridization method. Results: The frequencies of TNF $\alpha-850 \mathrm{~T}$, IL1A -889T, IL6 -174C allele and genotype did not differ between the AD and HC groups ( $p>0.05)$. IL6 -174C was not in HWE, and it was not analysed further. APOE $\varepsilon 4$ allele $(p=0.001)$ and $3 / 4$ and $4 / 4$ genotypes $(p=0.005)$ were more prevalent in $\mathrm{AD}$ patients. APOE $\varepsilon 4$ carriage increased the risk of $\mathrm{AD}$ (OR 2.65, $p=0.001$ ), while TNF $\alpha-850 \mathrm{~T}$ and IL1A $-889 \mathrm{~T}$ polymorphisms were not found as significant independent risk factors for AD. The presence of at least one IL1A $-889 \mathrm{~T}$ allele in combination with $\mathrm{APOE} \varepsilon 4+$ was associated with a lower risk of $\mathrm{AD}(\mathrm{OR} 2.24, p=0.047)$ than the carriage of APOE $\varepsilon 4+$ alone (OR 2.70, $p=0.015$ ). Conclusions: No significant differences of TNF $\alpha-850$, IL1A -889, and IL6 -174 polymorphisms frequencies were found between $\mathrm{AD}$ and control groups. In $\mathrm{APOE} \varepsilon 4$ carriers IL1A -889T polymorphism was found to reduce the AD risk determined by APOE $\varepsilon 4$ alone.
\end{abstract}

Keywords: TNF alpha; interleukin; polymorphism; APOE; Alzheimer's disease

\section{Introduction}

Alzheimer's disease $(\mathrm{AD})$ is a neurodegenerative multi-etiological disorder, where the amyloidogenic pathway is considered as the cornerstone of pathology. Tau protein-related changes and neuroinflammatory processes also play an important role in the progression of neurodegeneration. Enhancement of microglia activity was stated in vivo studies with AD patients [1], suggesting neuroinflammation as an early event in AD pathogenesis. It has also been noted that the levels of inflammatory cytokines (tumour necrosis factor-alpha (TNF $\alpha$ ), interleukin 1 (IL1), interleukin 6 (IL6), interleukin 8 (IL8), interleukin 10 (IL10), etc.) differ in AD patients compared with cognitively healthy people both in peripheral blood and cerebrospinal fluid (CSF) [2,3]. Neuroinflammatory processes may produce blood-brain barrier disruption in the early stage of AD pathology [4]. A wide range 
of genetic cytokine polymorphisms has been reported to be related to AD risk, but most of the data remain controversial or may be different due to specific ethnic DNA features [5].

$\mathrm{TNF} \alpha$ is one of the most investigated, neurodegeneration-linked proinflammatory factors. TNF $\alpha$ as a central mediator regulates different processes in the CNS, including neuronal development, cell survival, synaptic transmission, and neuronal ionic homeostasis [6]. TNF $\alpha$ is in close relation to amyloid beta $(\mathrm{A} \beta)$, which possibly stimulates Toll-like receptors and TNF $\alpha$ expression [7]. On the other hand, stimulation of neuroinflammation and TNF $\alpha$ signaling may induce or maintain the production of new pathogenic amyloid beta [6]. Several single-nucleotide polymorphisms (SNPs) of TNF $\alpha$ have been suggested as possible genetic risk factors for AD. The polymorphism in the promoter region $(-850)$ of $\mathrm{TNF} \alpha$ gene (TNF $\alpha-850 \mathrm{C}>\mathrm{T}$, rs1799724) has been associated with a higher risk of AD and synergistic effect with APOE epsilon 4 allele (APOE $\varepsilon 4$ ) [8-10]. However, the role of TNF $\alpha-850 \mathrm{~T}$ remains doubtful, as studies in other populations failed to confirm the association between AD risk and TNF $\alpha-850 \mathrm{~T}$ polymorphism [5,11].

IL1 is another proinflammatory cytokine associated with AD. It has been reported that IL1 restrains the function of cholinergic systems [12] and promotes the deposition of amyloid beta plaques and the accumulation of neurofibrillary tangles [13]. Polymorphism of the gene encoding IL1 alpha (IL1A) in its $5^{\prime}$ regulatory region IL1A $-889 \mathrm{C}>\mathrm{T}$ (rs1800587) has been reported to be associated with AD risk in Caucasians $[5,14,15]$, but the results of other studies have been inconsistent $[16,17]$.

IL6 has been suggested as a major proinflammatory cytokine in the CNS being important in the pathogenesis of the main neurodegenerative pathologies such as AD, Parkinson's disease, multiple sclerosis, Huntington's disease, and even some psychiatric disorders [18]. Overexpression of IL6 was observed in the brain of AD patients, where it was linked to amyloidogenesis $[19,20]$. IL6 was found to be elevated in the CSF and blood serum in AD cases [21], and it was demonstrated that IL6 levels could possibly indicate the severity of AD [22]. The protective role of IL6 -174G > C (rs1800795, Intron type) gene promoter polymorphism was observed [23-25], while other authors reported contrary results [26].

To our knowledge, there are no studies on the polymorphisms of inflammatory cytokines in the Lithuanian population in the context of dementia and AD risk. As single polymorphisms were not shown to be strongly linked to AD risk, we aimed at determining the associations between $\mathrm{AD}$ risk and TNF $\alpha$-850T (rs1799724), IL1A -889T (rs1800587), and IL6 -174C (rs1800795, Intron type) polymorphisms in combination with $\mathrm{APOE} \varepsilon 4$, which is still considered to be the strongest genetic risk factor for sporadic AD [27].

\section{Materials and Methods}

\subsection{Study Population}

The permission to conduct this case-control study was issued by the Kaunas Regional Biomedical Research Ethics Committee (No. BE-2-47, supplement No. P1-BE-2-47/2017).

The study was carried out in the Department of Neurology, Hospital of Lithuanian University of Health Sciences (LSMU) Kauno klinikos (Kaunas, Lithuania). A total of 217 persons aged more than 50 years, who had no major somatic disease (decompensated heart failure, terminal renal or hepatic dysfunction, or active cancer) or no severe mental disorder (psychotic type, severe depression), were included in the study. The AD group consisted of patients diagnosed with possible sporadic AD according to the NINCDS-ADRDA Alzheimer's Criteria [28]. All of them were screened for thyroid dysfunction and megaloblastic anemia. Exclusion criteria were prominent neurological deficit (severe paresis, ataxia, aphasia, etc.) and evident extrapyramidal signs (tremor, rigidity) or focal lesions in brain imaging (CT scan or MRI). Patients with AD were consulted together with a family member or other accompanying person. The control group (healthy controls, HC) consisted of persons with no cognitive disorder, matched by gender and age, who were under investigation or treated for others, but not a degenerative neurological disorder in the Department of Neurology. AD patients with their 
caregivers and controls were introduced with the study, received written information, and signed informed consent form.

Each participant completed a questionnaire on general demographic information and risk factors (age, duration of formal education in years, family history, lifestyle, and other diseases and conditions). Neurological status was evaluated by a standard neurological examination. All demented patients (AD group) were consulted by a psychiatrist in order to rule out pseudo dementia. Cognitive status was assessed using the Mini-Mental State Examination (MMSE) and the Blessed dementia scale [29,30]. Early stage AD (E-AD) was defined as mild dementia (MMSE score of 21-24) and minor disturbance of daily activities (Blessed's dementia scale score of 4-9), middle stage AD (M-AD), as moderate AD-type dementia (MMSE score of 11-20) and moderate daily life dysfunction (Blessed's dementia scale score of 10-22), and late AD, as severe dementia (MMSE score of 10 or less) and moderate-to-severe daily life disability (Blessed's scale score of 10 to 28). Patients both with early onset AD (EOAD, diagnosed with $\mathrm{AD}$ at the age of $<65$ years) and late onset $\mathrm{AD}$ (LOAD, aged 65 years and more) were included. The peripheral blood sample ( $5 \mathrm{~mL}$ of venous blood in EDTA collection tube) for DNA extraction was drawn by an experienced nurse.

\subsection{Genotyping}

DNA was extracted from peripheral blood lymphocytes by a standard procedure using an automatic DNA extraction kit (QIAmp ${ }^{\circledR}$ DNA Blood Mini Kit, Qiagen, Hilden, Germany).

$\mathrm{TNF} \alpha-850 \mathrm{C}>\mathrm{T}$ (rs1799724) polymorphism was detected by the polymerase chain reaction (PCR) and restriction fragment length polymorphism (RFLP) analysis. TNF $\alpha-850$ SNP genotype was determined by PCR amplification in a total volume of $30 \mu \mathrm{L}$, containing HotStart Taq Master Mix (Qiagen, $1000 \mathrm{U}$ ), each forward and reverse TNF $\alpha-850$ primers $(10 \mu \mathrm{M})$, under the following conditions: 1 cycle of $95{ }^{\circ} \mathrm{C}$ for $15 \mathrm{~min}, 35$ cycles of $94{ }^{\circ} \mathrm{C}$ for $45 \mathrm{~s}, 60^{\circ} \mathrm{C}$ for $30 \mathrm{~s}$, and $72{ }^{\circ} \mathrm{C}$ for $45 \mathrm{~s}$, followed by 1 cycle of $72{ }^{\circ} \mathrm{C}$ for $5 \mathrm{~min}$. The primers $5^{\prime}$-TCG AGT ATC GGG GAC CCC CCG TT-3' (underline denotes mismatch) and 5'-CCA GTG TGT GGC CAT ATC TTC TT-3' (modified from the initially published [31]) were used (from Integrated DNA Technologies, BVBA, Leuven, Belgium). Amplified TNF $\alpha-850$ was digested at $37^{\circ} \mathrm{C}$ for $4 \mathrm{~h}$ using $500 \mathrm{U}$ HincII (concentration $10 \mathrm{U} / \mu \mathrm{L}$ ) (restriction sequence GTT $\triangle \mathrm{AAC}$ ), separated on $4 \%$ agarose gels at $100 \mathrm{~V}(60 \mathrm{~min})$ and stained with ethidium bromide to reveal DNA fragments with migration patterns specific for each allele (C allele-105 bp and 23 bp, T allele-128 bp) [32] (FastDigest Hinc II, Thermo Fisher Scientific, Life Technologies Ltd, Paisley, UK).

Genotyping of IL1A -889 (rs1800587) and IL6 -174 (rs1800795, Intron type) SNP's polymorphism was performed using a real-time PCR method. PCR amplification was done in a total volume of $25 \mu \mathrm{L}$, containing Type-it Fast SNP Probe PCR Master Mix $(12.5 \mu \mathrm{L})$, primer-probe mix $(1.25 \mu \mathrm{L})$, DNA (20 ng), and RNase-free water, by the following PCR cycling program: 1 cycle of $95^{\circ} \mathrm{C}$ for $5 \mathrm{~min}$ for initial PCR activation, followed by 40 cycles of $95^{\circ} \mathrm{C}$ for $15 \mathrm{~s}$ and $60^{\circ} \mathrm{C}$ for $30 \mathrm{~s}$ (Type-it Fast SNP Probe PCR Kit, Qiagen). After PCR amplification, end-point plate reading was completed on a real-time PCR instrument (Qiagen RotorGene Q, Qiagen, Hilden, Germany) based on fluorescence measurements. The allele detected by VIC was IL1A -889A (T) and IL6 -174C, the allele detected by FAM was IL1A -889G (C) and IL6 -174G. The primers GAT TTT TAC ATA TGA GCC TTC AAT G[A/G]T GTT GCC TGG TTA CTA TTA TTA AAG (IL1A -889), and ACT TTT CCC CCT AGT TGT GTC TTG C[C/G]A TGC TAA AGG ACG TCA CAT TGC ACA (IL6 -174) were used (TaqMan ${ }^{\circledR}$, ThermoFischer Scientific, Life Technologies Ltd, Paisley, UK).

APOE $\varepsilon$ allele was determined via the hybridization method according to the manufacturer's protocol (GenoType ApoE, ver. 1.0, 2015, Hain Lifescience GmbH, Qiagen, Nehren, Germany). 


\subsection{Statistical Analysis}

Data were analyzed using the Statistical Package for the Social Sciences (IBM ${ }^{\circledR}$ SPSS Statistics, IBM, Armonk, NY, USA) version 23.0 software. Sample size was calculated using the formula:

$$
n=\left[\left(Z_{\alpha / 2}+Z_{\beta}\right)^{2} \times\{(p 1(1-p 1)+(p 2(1-p 2))\}] /(p 1-p 2)^{2}\right.
$$

where $n=$ sample size required in each group, $p 1=0.18, p 2=0.35, p 1-p 2=$ significant difference $=0.17$ (according to expected genotype frequency), $Z_{\alpha / 2}$ : for level of significance $5 \%$ this is $1.96, Z_{\beta}$ : for $80 \%$ power is 0.84 . Based on the above formula, the sample size required per group is 102 patients (204 persons in total). The normality of data distribution of continuous variables was tested by the Shapiro-Wilk test. Normally distributed variables (Shapiro-Wilk test $p<0.05$ ) were expressed as mean (standard deviation, SD). For variables that were not normally distributed, nonparametric tests were applied and results are expressed as median (IQR). Results are presented as numbers (percentages) for categorical variables. Allele frequencies were tested for the Hardy-Weinberg equilibrium (HWE). Pearson's chi-square $\left(\chi^{2}\right)$ test was used to compare genotype and allele frequencies between AD and HC groups. Binary logistic regression analysis, adjusted for age and gender, was performed to estimate the possible effect of TNF $\alpha-850 \mathrm{~T}$, IL1A -889T, IL6 -174C polymorphisms and combinations of cytokine polymorphisms with $\mathrm{APOE} \varepsilon 4$ on $\mathrm{AD}$ risk in the $\mathrm{AD}$ patients and controls (development of $\mathrm{AD}$ as a dependent variable). Odds ratios (ORs) with $95 \%$ confidence intervals ( $95 \% \mathrm{CI}$ ) were calculated. The level of significance level was set at $<0.05$.

\section{Results}

A total of 217 persons were included in the study. All the participants were Caucasian, most of them were of Lithuanian origin. AD patients and controls were matched for age and gender (Table 1).

Table 1. Characteristics of the study population.

\begin{tabular}{lccc}
\hline \multicolumn{1}{c}{ Characteristic } & AD $(\boldsymbol{n}=\mathbf{1 0 7})$ & HC $(\boldsymbol{n}=\mathbf{1 1 0})$ & $p$ \\
\hline Age, mean (SD), years & $73.77(7.3)$ & $73.03(7.5)$ & 0.462 \\
Gender, $n(\%)$ & & & \\
$\quad$ Male & $35(32.7)$ & $37(33.6)$ & 0.885 \\
Female & $72(67.3)$ & $73(66.4)$ & \\
APOE $4+, n(\%)$ & $51(48.6)$ & $29(26.6)$ & 0.001 \\
MMSE, median (IQR), score & $19(15-27)$ & $28(28-29.25)$ & $<0.001$ \\
Education, median (IQR), years & $12(8-15)$ & $14(11-16)$ & 0.004 \\
BMI, median (IQR), kg/m ${ }^{2}$ & $25.45(23.18-28.93)$ & $27.36(24.29-30.9)$ & 0.009 \\
Family history of dementia, $n(\%)$ & $36(33.6)$ & $16(14.5)$ & 0.001 \\
\hline
\end{tabular}

AD-Alzheimer's disease, HC—healthy controls, MMSE-Mini-Mental State Examination, BMI—body mass index, APOE $\varepsilon 4+$ - subjects with at least one APOE epsilon 4 allele. Normally distributed data were compared with the Student's $t$ test, non-normally distributed continuous data, with the Mann-Whitney $U$ test, and categorical data, with Pearson's chi-square test.

Patients with AD group had lower BMI and fewer years of education, and a family history of dementia was documented more frequently among patients with AD. As expected, inheritance of at least one APOE epsilon 4 allele (APOE $\varepsilon 4+$ ) was more prevalent in the AD group (Table 1). APOE $\varepsilon$ 3/4 and $4 / 4$ genotypes were more frequent in $\mathrm{AD}$ patients, while $\mathrm{APOE} \varepsilon 3 / 3$ was more prevalent in the controls group (Table 2).

In the AD group, there were 17 patients (15.9\%) with early onset $\mathrm{AD}$ (EOAD) and 90 patients $(84.1 \%)$ with late onset $\mathrm{AD}$ (LOAD). Of the AD patients, $29 \%(n=31)$ had mild $\mathrm{AD}, 62.6 \%(n=67)$ had moderate $\mathrm{AD}$, and $8.4 \%(n=9)$ had severe $\mathrm{AD}$. 
Table 2. Distribution of APOE $\varepsilon$ allele and genotype between AD patients and controls.

\begin{tabular}{cccc}
\hline APOE & AD $(n=\mathbf{1 0 5})$ & HC $(n=\mathbf{1 0 9})$ & $p$ \\
\hline Genotype, $n(\%)$ & & & \\
$2 / 2$ & $1(1.0)$ & $2(1.8)$ & 0.005 \\
$2 / 3$ & $7(6.7)$ & $15(13.8)$ & \\
$3 / 3$ & $46(43.8)$ & $63(57.8)$ & \\
$3 / 4$ & $44(41.9)$ & $25(22.9)$ & \\
$4 / 4$ & $4(3.8)$ & $0(0)$ & \\
$2 / 4$ & $3(2.9)$ & $4(3.7)$ & \\
Alleles, $n(\%)$ & & & \\
2 & $12(5.7)$ & $23(10.6)$ & \\
3 & $143(68.1)$ & $166(76.1)$ & 0.001 \\
4 & $55(26.2)$ & $29(13.3)$ & \\
\hline
\end{tabular}

AD—Alzheimer's disease group, HC—healthy controls. Values were compared with Pearson's chi-square test.

The distribution of TNF $\alpha-850$ and IL1A -889 alleles and genotypes followed the Hardy-Weinberg equilibrium (AD group HWE: TNF $\alpha-p=0.69$, IL1A $-p=0.97$, HC group HWE: TNF $\alpha-p=0.83$, IL1A $-p=0.61$ ). The distribution of IL6 -174 did not meet HWE both in AD patients and controls $(p<0.05)$, thus it was not analysed further than evaluation of allele and genotype frequencies. The very homogenous ethnic origin of subjects in our study possibly could explain that, because IL6 -174 SNP genotype and allele distribution varies considerably according to the population ethnicity [33]. No significant difference was found in the distribution of cytokine genotype and allele between the $\mathrm{AD}$ and control groups (Table 3).

Table 3. Distribution of TNF $\alpha-850$, IL1A -889 and IL6 -174 alleles and genotypes between AD patients and controls.

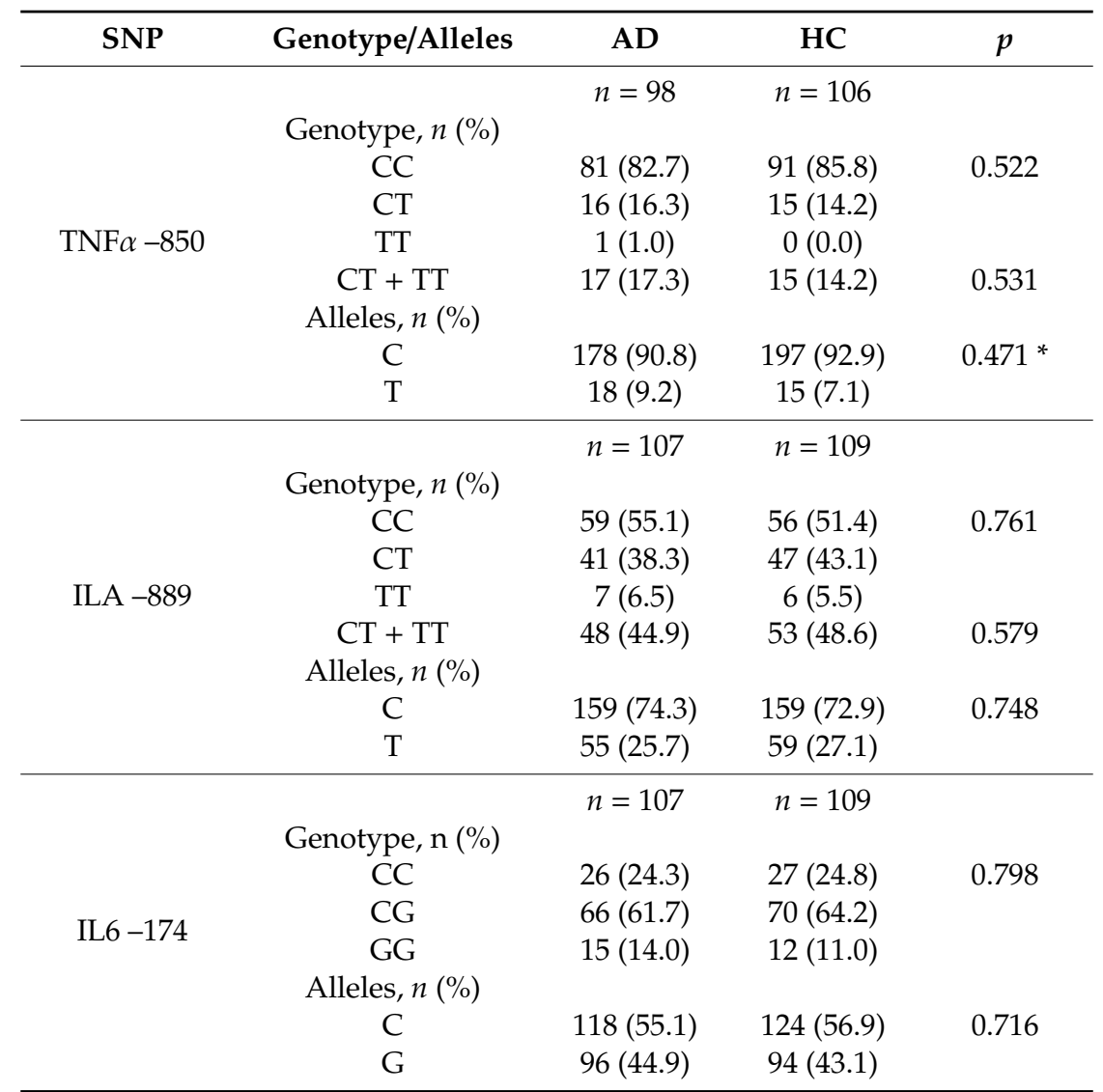

AD-Alzheimer's disease group, HC-healthy controls. Genotype and allele frequencies were compared using the chi-square test and Fisher's exact test $\left({ }^{*}\right)$. 
There were no significant differences in the frequencies of genotypes among subjects who had at least one allele of the expected polymorphism (dominant genotype model: TNF $\alpha-850(\mathrm{TT}+\mathrm{CT}$ ), IL1A -889(TT + TC)). Moreover, there were no significant differences comparing the distribution of polymorphisms between the patients with EOAD (age at collection: mean $61.59 \pm 4.23$, median 63.0, min. 54, max. 68 years) and LOAD (age at collection: mean $75.99 \pm 5.11$, median 75.0, min. 66, max. 88 years, age EOAD vs LOAD $p=0.001$ ) (Table 4 ).

Table 4. Distribution of TNF $\alpha-850$ and IL1A -889 alleles and genotypes between EOAD and LOAD patients and controls.

\begin{tabular}{cccccc}
\hline SNP & Genotype/Alleles & EOAD & LOAD & HC & $p$ \\
\hline & Genotype, $n(\%)$ & $n=17$ & $n=81$ & $n=106$ & \\
CC & $16(94.1)$ & $65(80.2)$ & $91(85.8)$ & $0.413^{1}$ \\
TNF $\alpha-850$ & CT & $1(5.9)$ & $15(18.5)$ & $15(14.2)$ & $0.696^{2}$ \\
& TT & $0(0.0)$ & $1(1.2)$ & $0(0.0)$ & $0.363^{3}$ \\
& Alleles, $n(\%)$ & & & & \\
C & $33(97.1)$ & $145(89.5)$ & $197(92.9)$ & 0.322 \\
T & $1(2.9)$ & $17(10.5)$ & $15(7.1)$ & \\
& Genotype, $n(\%)$ & $n=17$ & $n=90$ & $n=109$ & \\
CC & $9(52.9)$ & $50(55.6)$ & $56(51.4)$ & $0.418^{1}$ \\
CT & $8(47.1)$ & $33(36.6)$ & $47(43.1)$ & $0.608^{2}$ \\
TT & $0(0.0)$ & $7(7.8)$ & $6(5.5)$ & $0.588^{3}$ \\
& Alleles, $n(\%)$ & & & \\
C & $26(76.5)$ & $133(73.9)$ & $159(72.9)$ & 0.833 \\
T & $8(23.5)$ & $47(26.1)$ & $59(27.1)$ & \\
\hline
\end{tabular}

EOAD—early onset Alzheimer's disease group, LOAD—late onset Alzheimer's disease group, HC—healthy controls. Genotype and allele frequencies were compared using the chi-square test. $p$-EOAD vs. LOAD (allele), $p^{1}-\mathrm{EOAD}$ vs. LOAD, $p^{2}$-EOAD vs. HC, $p^{3}$ - LOAD vs. HC (genotype)

Binary logistic regression analysis, adjusted for age and gender (independent variables), showed that the presence of $\mathrm{APOE} \varepsilon 4$ allele was associated with more than a 2-fold higher risk of AD (OR 2.65, 95\% CI 1.49-4.70, $p=0.001)$. TNF $\alpha-850 \mathrm{~T}$ and IL1A -889T polymorphisms were not associated with $\mathrm{AD}$ risk $(p>0.05)$ (Table 5$)$, and entering APOE $\varepsilon 4$ as an additional covariate (model ${ }^{2}$ with age, gender, and APOE as independent variables) into logistic regression analysis did not have any significant impact for associations (Table 5).

Table 5. Logistic regression analysis of TNF $\alpha-850 \mathrm{C}>\mathrm{T}$ and IL1A $-889 \mathrm{C}>\mathrm{T}$ SNPs in Alzheimer's disease and control groups.

\begin{tabular}{|c|c|c|c|c|c|c|c|}
\hline SNPs & & odel & $\beta$ & SE & Wald Statistics & OR $(95 \%$ CI $)$ & $p$ \\
\hline $\mathrm{TNF} \alpha-850 \mathrm{C}>\mathrm{T}$ & $\begin{array}{c}\mathrm{CC} \\
\mathrm{CT}+\mathrm{TT}\end{array}$ & $\begin{array}{c}\text { Ref. } \\
\text { dominant }^{1} \\
\text { dominant }^{2}\end{array}$ & $\begin{array}{l}0.23 \\
0.33\end{array}$ & $\begin{array}{l}0.39 \\
0.41\end{array}$ & $\begin{array}{l}0.37 \\
0.66\end{array}$ & $\begin{array}{l}1.26(0.59-2.70) \\
1.39(0.62-3.09)\end{array}$ & $\begin{array}{l}0.545 \\
0.417\end{array}$ \\
\hline IL1A $-889 \mathrm{C}>\mathrm{T}$ & $\begin{array}{c}\mathrm{CC} \\
\mathrm{CT}+\mathrm{TT} \\
\mathrm{CC}+\mathrm{CT} \\
\mathrm{TT}\end{array}$ & $\begin{array}{l}\text { Ref. } \\
\text { dominant }^{1} \\
\text { dominant }^{2} \\
\quad \text { Ref. } \\
\text { recessive }^{1} \\
\text { recessive }^{2}\end{array}$ & $\begin{array}{l}-0.15 \\
-0.14 \\
0.19 \\
0.21\end{array}$ & $\begin{array}{l}0.27 \\
0.28 \\
0.58 \\
0.59\end{array}$ & $\begin{array}{l}0.11 \\
0.13\end{array}$ & $\begin{array}{l}0.86(0.50-1.47) \\
0.87(0.50-1.51) \\
1.21(0.39-3.73) \\
1.23(0.39-3.93)\end{array}$ & $\begin{array}{c}0.585 \\
0.61\end{array}$ \\
\hline
\end{tabular}

SNP—single nucleotide polymorphism, dominant ${ }^{1}$, recessive ${ }^{1}$ — model for binary logistic regression, adjusted for age and gender, dominant ${ }^{2}$, recessive ${ }^{2}$ - model for binary logistic regression, adjusted for age, gender and carriage of at least one $\mathrm{APOE} \varepsilon 4$ allele, Ref.—reference group, $\beta$-coefficients beta, SE—standard error, OR—odds ratio, $\mathrm{CI}$-confidence interval. 
The presence of at least one IL1A $-889 \mathrm{~T}$ allele in combination with APOE $\varepsilon 4+$ was associated with a lower risk of $\mathrm{AD}(\mathrm{OR} 2.24, p=0.047)$ than the carriage of APOE $\varepsilon 4+$ alone (OR 2.70, $p=0.015)$ (Table 6).

Table 6. Logistic regression analysis of the interaction between APOE $\varepsilon 4$ allele and polymorphisms of $\mathrm{TNF} \alpha$ and IL1A in Alzheimer's disease and control groups.

\begin{tabular}{|c|c|c|c|c|c|c|}
\hline & & \multicolumn{2}{|c|}{ Frequencies } & \multicolumn{3}{|c|}{ Logistic Regression } \\
\hline \multicolumn{2}{|c|}{ Genotypes } & $\begin{array}{c}\text { HC } \\
n(\%)\end{array}$ & $\begin{array}{c}\mathrm{AD} \\
n(\%)\end{array}$ & $\beta$; SE; Wald & $\begin{array}{c}\text { Odds Ratio } \\
\text { (95\% CI) }\end{array}$ & $p$ Value \\
\hline $\mathrm{APOE} \varepsilon 4$ & $\mathrm{TNF} \alpha-850 \mathrm{~T}$ & $n=105$ & $n=96$ & & & \\
\hline- & - & $66(62.9)$ & $39(40.6)$ & & Ref. & 0.005 \\
\hline- & + & $13(12.4)$ & $10(10.4)$ & $\begin{array}{l}0.26 ; 0.47 \\
\quad 0.32\end{array}$ & $\begin{array}{c}1.30 \\
(0.52-3.25)\end{array}$ & 0.572 \\
\hline+ & - & $24(22.9)$ & $41(42.7)$ & $\begin{array}{c}1.06 ; 0.33 \\
10.55\end{array}$ & $\begin{array}{c}2.89 \\
(1.52-5.49)\end{array}$ & 0.001 \\
\hline+ & + & $2(1.9)$ & $6(6.3)$ & $\begin{array}{c}1.63 ; 0.84 \\
3.73\end{array}$ & $\begin{array}{c}5.08 \\
(0.98-26.40)\end{array}$ & 0.053 \\
\hline $\mathrm{APOE} \varepsilon 4$ & IL1A -889T & $n=109$ & $n=105$ & & & \\
\hline- & - & $42(38.53)$ & $30(28.57)$ & & Ref. & 0.012 \\
\hline- & + & $38(34.86)$ & $24(22.86)$ & $\begin{array}{c}-0.12 ; 0.35 ; \\
0.12\end{array}$ & $\begin{array}{c}0.88 \\
(0.44-1.77)\end{array}$ & 0.728 \\
\hline+ & - & $14(12.85)$ & $27(25.71)$ & $\begin{array}{l}0.99 ; 0.41 \\
5.96\end{array}$ & $\begin{array}{c}2.7 \\
(1.22-5.99)\end{array}$ & 0.015 \\
\hline+ & + & $15(13.76)$ & $24(22.86)$ & $\begin{array}{l}0.81 ; 0.41 \\
\quad 3.93\end{array}$ & $\begin{array}{c}2.24 \\
(1.01-4.97)\end{array}$ & 0.047 \\
\hline
\end{tabular}

AD-Alzheimer's dementia group, HC-healthy controls, APOE $\varepsilon 4+$ - subjects with at least one $\varepsilon 4$ allele, TNF $\alpha$ -850T-TT homozygotes + CT heterozygotes (dominant model), IL1A -889T-TT homozygotes + CT heterozygotes (dominant model), Ref.-reference group, $\beta$-coefficients beta; SE—standard error, OR—odds ratio, $\mathrm{CI} —$ confidence interval, significant $\mathrm{OR}$ and $p$ value.

Multivariate logistic regression analysis (backward method) revealed that APOE 44 allele was associated with higher AD risk (OR 2.80, 95\% CI 1.49-5.26, $p=0.001$ ), while longer duration of education (OR 0.87, 95\% CI 0.80-0.94, $p=0.001$ ) and higher body mass index (OR 0.91, 95\% CI 0.84-0.97, $p=0.006)$ had a protective effect.

\section{Discussion}

Searching for certain combinations of AD-related polymorphisms has been a challenge for many researchers. The main reason forcing investigators to put in the effort is the ambition to predict disease in its early stages before cognitive decline is observed. This could lead to timely treatment and reduce the burden of Alzheimer's dementia. In this study, we investigated the relation of proinflammatory cytokine polymorphisms to AD risk in association with the carriage of APOE $\varepsilon 4$ allele. This study is the first one to evaluate the impact of TNF $\alpha$, IL1, and IL6 polymorphisms on AD risk in the Lithuanian population. Our results on the prevalence of $\mathrm{APOE} \varepsilon 4$ allele correspond to other published data showing that the prevalence of this allele ranges from $40 \%$ to $50 \%$ among AD cases and support the recognition of APOE as the main genetic risk factor of AD susceptibility [27]. We found the epsilon 4 allele to be almost 2-fold more frequent in patients with $\mathrm{AD}$, and the prevalence of $\mathrm{APOE} \varepsilon$ genotypes $3 / 4,4 / 4$ was higher in this group as well. It has been reported that APOE $\varepsilon 4$ is associated with sporadic and familial $\mathrm{AD}$ [34-36], and the carriage of $\varepsilon 4$ allele may determine a higher risk to develop AD at younger age [37]. Patients with both late and early onset AD were included in our study, but our data do not let us make explicit conclusions on the influence of the APOE polymorphism according to the age of disease onset. However, clinical observations suggest that in patients with at least one $\varepsilon 4$ allele, 
cognitive functions tend to deteriorate in a more aggressive way and this could be a focus for further investigations. We also found that APOE $\varepsilon 2$ allele and $\varepsilon 2 / 2,2 / 3$ genotypes were more prevalent in healthy controls, and these findings are in line with the results of studies in other populations [38,39]. Thus, $\mathrm{APOE} 22$ could be an indirect protective biomarker of AD development, useful to know in the clinical settings.

The results of TNF $\alpha-850 \mathrm{~T}$ polymorphism revealed some tendency, comparing the distribution of TT homozygotes together with CT heterozygotes (dominant model) between AD and healthy control groups. We also observed that the combination of $\mathrm{APOE} \varepsilon 4+$ and $\mathrm{TNF} \alpha-850 \mathrm{~T}$ could increase the risk of AD reasonably, and it just slightly miss significance $(p=0.053)$, possibly because of the sample size. This statement would be in line with data reported by other authors stating that TNF $\alpha-850 \mathrm{~T}$ allele with $\mathrm{APOE} \varepsilon 4$ has a synergistic effect on greater AD risk in European populations [8-10]. The Australian study on patients with late onset $\mathrm{AD}$ also noted that $\mathrm{TNF} \alpha-850 \mathrm{~T}$ contributed to $\mathrm{AD}$ risk independently of APOE $\varepsilon 4$ carriage [32]. Still data are inconsistent to make definite conclusions as other studies in different populations have reported opposite results and have not proven the association between AD risk and TNF $\alpha-850 \mathrm{~T}$ polymorphism [11,40]. The inconsistent findings probably could be explained by ethnic differences and diversity of study design or certain peculiarities of patient involvement in the research (for example, different diagnostic criteria were used, patients only with late onset or not specified sporadic $\mathrm{AD}$ were involved, or only cases with $\mathrm{AD}$ verified by pathological findings).

The current study showed contradictory results on the polymorphisms of both IL1A -889T and IL6 -174C. The prevalence of alleles (IL1A -889 C and T, IL6 -174C and G) was similar to that reported in other Europe populations [33]. The distribution of genotypes and alleles of those SNPs had no significant difference in AD versus controls (chi square test, $p>0.05$ ). IL1A -889T had no significant impact on AD risk when evaluating separately. However, in APOE 4 carriers, IL1A polymorphism had a significant influence on AD risk. Polymorphism of IL1A -889T (at least one T allele) was associated with $\mathrm{AD}$ risk in $\mathrm{APOE} \varepsilon 4+$ cases, but the effect was the reverse, antagonistic to APOE, suggesting IL1A $-889 \mathrm{~T}$ could lower the $\mathrm{AD}$ risk. This is in disagreement with the conclusions of a recent meta-analysis by Dong et al. [41], where the significant correlation between IL1A polymorphism and AD risk was stated and $\mathrm{T}$ allele considered to be a factor for AD susceptibility. Of course, we must interpret these our results with caution, because in the combination with IL1A -889T, inheritance of APOE 4 , but not the 1L1A polymorphism, still had a decisive effect on AD risk. On the other hand, different authors also declare negative results according to IL1A polymorphism and AD risk [42-44]. Specific combinations of polymorphisms due to the ethnicity of patients could possibly explain the discrepancy of the results, and the age of disease onset could be considered too. Rebeck reported that IL1A -889TT genotype was associated with an earlier age of AD onset and increased risk of EOAD [45].

The impact of the IL6 -174C polymorphism on AD risk was not analysed in our study because of its deviation from Hardy-Weinberg equilibrium. In previous studies, the protective role of the CC genotype in AD manifestation has been documented [23,24]. Although in several studies, the role of IL6 polymorphism has also been argued, and the evident association has not been established [26,46]. Certainly, we have to keep in mind that the small sample size of our study might impact the results, and there is the possibility of false negative results in the differences between genotype and allele distributions. On the other hand, there is the possibility of false positive results in estimation of $\mathrm{TNF} \alpha$, IL1A polymorphisms and APOE interaction, as no correction for multiple testing was applied. Further studies are needed to confirm or contradict our observations. Despite inconsistent data on associations between the polymorphisms of proinflammatory factors and AD risk, associations with blood and CSF findings [47,48], possible specific AD genetic profiles [49] make further investigations worthy, expecting new biomarkers to be suggestive of Alzheimer's dementia. Precise selection of study cases targeted on age of disease onset, BMI, and education could help disclose beneficial information on $\mathrm{AD}$ risk. Our study revealed the protective role of longer duration of education, and this in agreement with the results of other investigators [50,51]. Moreover, we found a significant impact of BMI on AD risk. Patients with lower $\mathrm{BMI}$ were at greater risk of $\mathrm{AD}$, and from the first glance it looks conflicting 
with the concept of obesity as a risk factor for dementia [52-54]. It was suggested that metabolism changes determined by obesity in middle age of lifespan could be in relation to neuroinflammation and structural brain grey matter changes [52,53]. However, a recent review on 39 cohort studies with more than 1.3 million individuals indicates that higher BMI is associated with an elevated risk of dementia only if it would be evaluated two decades or more before cognitive disturbance. Lower BMI could reflect the higher dementia risk assessing BMI more close (less than 10 years) to the clinical cognitive decline [54]. The main limitation of the study was a quite small sample size. More valuable insights could be expected if the study data could be interpreted in the context with other biomarkers of AD such as CSF or blood amyloid and tau protein level profile or biomarkers imaging (Abeta or Tau PET) findings.

\section{Conclusions}

In conclusion, we found no significant differences in the frequencies of polymorphisms of proinflammatory cytokines TNF $\alpha-850 \mathrm{~T}$, IL1A -889T, and IL6 -174C between AD patients and persons with intact cognitive functions. TNF $\alpha-850 \mathrm{~T}$, IL1A -889T polymorphisms had no significant impact on AD risk, thus according to our data, TNF $\alpha-850 \mathrm{~T}$ and IL1A - 889Tcannot be considered as independent risk factors for developing AD. The carriage of the APOE $\varepsilon 4$ allele was associated with greater AD risk. Longer duration of education and greater BMI appeared to have a protective role in AD. In APOE $\varepsilon 4$-positive persons, the inheritance of IL1A -889T polymorphism (at least one T allele) was found to reduce the AD risk determined by the possession of APOE $\varepsilon 4$ alone.

Author Contributions: G.P.-Methodology, Investigation, Data curation, Writing-original draft, review, and editing. K.P.-Conceptualization, Writing-review and editing. D.R.-Conceptualization, Methodology, Writing-review and editing, Supervision.

Funding: The study was partly funded by the Research Council of Lithuania grant number LIG-04/2012 (MALPAMA).

Acknowledgments: No other support was received from the third party.

Conflicts of Interest: The authors declare no conflict of interest.

\section{References}

1. Cagnin, A.; Brooks, D.J.; Kennedy, A.M.; Gunn, R.N.; Myers, R.; Turkheimer, F.E.; Jones, T.; Banati, R.B. In-vivo measurement of activated microglia in dementia. Lancet 2001, 358, 461-467. [CrossRef]

2. Brosseron, F.; Krauthausen, M.; Kummer, M.; Heneka, M.T. Body fluid cytokine levels in mild cognitive impairment and Alzheimer's disease: A comparative overview. Mol. Neurobiol. 2014, 50, 534-544. [CrossRef] [PubMed]

3. Tarkowski, E.; Liljeroth, A.M.; Minthon, L.; Tarkowski, A.; Wallin, A.; Blennow, K. Cerebral pattern of proand anti-inflammatory cytokines in dementias. Brain Res. Bull. 2003, 61, 255-260. [CrossRef]

4. Ott, B.R.; Jones, R.N.; Daiello, L.A.; de la Monte, S.M.; Stopa, E.G.; Johanson, C.E.; Denby, C.; Grammas, P. Blood-Cerebrospinal Fluid Barrier Gradients in Mild Cognitive Impairment and Alzheimer's Disease: Relationship to Inflammatory Cytokines and Chemokines. Front. Aging Neurosci. 2018, 10, 245. [CrossRef] [PubMed]

5. Su, F.; Bai, F.; Zhang, Z. Inflammatory Cytokines and Alzheimer's Disease: A Review from the Perspective of Genetic Polymorphisms. Neurosci. Bull. 2016, 32, 469-480. [CrossRef]

6. Park, K.M.; Bowers, W.J. Tumor necrosis factor-alpha mediated signaling in neuronal homeostasis and dysfunction. Cell Signal. 2010, 22, 977-983. [CrossRef]

7. Jin, J.J.; Kim, H.D.; Maxwell, J.A.; Li, L.; Fukuchi, K. Toll-like receptor 4-dependent upregulation of cytokines in a transgenic mouse model of Alzheimer's disease. J. Neuroinflamm. 2008, 5, 23. [CrossRef]

8. McCusker, S.M.; Curran, M.D.; Dynan, K.B.; McCullagh, C.D.; Urquhart, D.D.; Middleton, D.; Patterson, C.C.; McIlroy, S.P.; Passmore, A.P. Association between polymorphism in regulatory region of gene encoding tumour necrosis factor alpha and risk of Alzheimer's disease and vascular dementia: A case-control study. Lancet 2001, 357, 436-439. [CrossRef] 
9. Laws, S.M.; Perneczky, R.; Wagenpfeil, S.; Müller, U.; Förstl, H.; Martins, R.N.; Kurz, A.; Riemenschneider, M. TNF polymorphisms in Alzheimer disease and functional implications on CSF beta-amyloid levels. Hum. Mutat. 2005, 26, 29-35. [CrossRef]

10. Di Bona, D.; Candore, G.; Franceschi, C.; Licastro, F.; Colonna-Romano, G.; Cammà, C.; Lio, D.; Caruso, C. Systematic review by meta-analyses on the possible role of TNF-alpha polymorphisms in association with Alzheimer's disease. Brain Res. Rev. 2009, 61, 60-68. [CrossRef]

11. Infante, J.; Llorca, J.; Berciano, J.; Combarros, O. No synergistic effect between -850 tumor necrosis factor-alpha promoter polymorphism and apolipoprotein E epsilon 4 allele in Alzheimer's disease. Neurosci. Lett. 2002, 328, 71-73. [CrossRef]

12. Li, Y.; Liu, L.; Kang, J.; Sheng, J.G.; Barger, S.W.; Mrak, R.E.; Griffin, W.S. Neuronal-glial interactions mediated by interleukin-1 enhance neuronal acetylcholinesterase activity and mRNA expression. J. Neurosci. 2000, 20, 149-155. [CrossRef] [PubMed]

13. Griffin, W.S.; Mrak, R.E. Interleukin-1 in the genesis and progression of and risk for development of neuronal degeneration in Alzheimer's disease. J. Leukoc. Biol. 2002, 72, 233-238. [PubMed]

14. Li, X.Q.; Zhang, J.W.; Zhang, Z.X.; Chen, D.; Qu, Q.M. Interleukin-1 gene cluster polymorphisms and risk of Alzheimer's disease in Chinese Han population. J. Neural. Transm. 2004, 111, 1183-1190. [CrossRef]

15. Qin, X.; Peng, Q.; Zeng, Z.; Chen, Z.; Lin, L.; Deng, Y.; Huang, X.; Xu, J.; Wu, H.; Huang, S.; et al. Interleukin-1A -889C/T polymorphism and risk of Alzheimer's disease: A meta-analysis based on 32 case-control studies. J. Neurol. 2012, 259, 1519-1529. [CrossRef]

16. Serretti, A.; Olgiati, P.; Politis, A.; Malitas, P.; Albani, D.; Dusi, S.; Polito, L.; De Mauro, S.; Zisaki, A.; Piperi, C.; et al. Lack of association between interleukin-1 alpha rs1800587 polymorphism and Alzheimer's disease in two Independent European samples. J. Alzheimers Dis. 2009, 16, 181-187. [CrossRef]

17. Yildiz, S.H.; Erdogan, M.O.; Artan, S.; Solak, M.; Yaman, M.; Ozbabalik, B.D.; Terzi, E.S. Association of Alzheimer's Disease with APOE and IL- $1 \alpha$ Gene Polymorphisms. Am. J. Alzheimers Dis. Other Demen. 2015, 30, 756-761. [CrossRef]

18. Erta, M.; Quintana, A.; Hidalgo, J. Interleukin-6, a major cytokine in the central nervous system. Int. J. Biol. Sci. 2012, 8, 1254-1266. [CrossRef]

19. Hampel, H.; Haslinger, A.; Scheloske, M.; Padberg, F.; Fischer, P.; Unger, J.; Teipel, S.J.; Neumann, M.; Rosenberg, C.; Oshida, R.; et al. Pattern of interleukin-6 receptor complex immunoreactivity between cortical regions of rapid autopsy normal and Alzheimer's disease brain. Eur. Arch. Psychiatry Clin. Neurosci. 2005, 255, 269-278. [CrossRef]

20. Strauss, S.; Bauer, J.; Ganter, U.; Jonas, U.; Berger, M.; Volk, B. Detection of interleukin-6 and alpha 2-macroglobulin immunoreactivity in cortex and hippocampus of Alzheimer's disease patients. Lab. Investig. 1992, 66, 223-230.

21. Sun, Y.X.; Minthon, L.; Wallmark, A.; Warkentin, S.; Blennow, K.; Janciauskiene, S. Inflammatory markers in matched plasma and cerebrospinal fluid from patients with Alzheimer's disease. Dement. Geriatr. Cogn Disord. 2003, 16, 136-144. [CrossRef] [PubMed]

22. Lai, K.S.P.; Liu, C.S.; Rau, A.; Lanctôt, K.L.; Köhler, C.A.; Pakosh, M.; Carvalho, A.F.; Herrmann, N. Peripheral inflammatory markers in Alzheimer's disease: A systematic review and meta-analysis of 175 studies. J. Neurol. Neurosurg. Psychiatry 2017, 88, 876-882. [CrossRef] [PubMed]

23. Fontalba, A.; Gutierrez, O.; Llorca, J.; Mateo, I.; Vazquez-Higuera, J.L.; Berciano, J.; Fernández-Luna, J.L.; Combarros, O. Gene-gene interaction between CARD8 and interleukin-6 reduces Alzheimer's disease risk. J. Neurol. 2009, 256, 1184-1186. [CrossRef] [PubMed]

24. Flex, A.; Giovannini, S.; Biscetti, F.; Liperoti, R.; Spalletta, G.; Straface, G.; Landi, F.; Angelini, F.; Caltagirone, C.; Ghirlanda, G.; et al. Effect of proinflammatory gene polymorphisms on the risk of Alzheimer's disease. Neurodegener. Dis. 2014, 13, 230-236. [CrossRef]

25. Hua, Y.; Guo, X.; Huang, Q.; Kong, Y.; Lu, X. Association between interleukin-6 -174G/C polymorphism and the risk of Alzheimer's disease: A meta-analysis. Int. J. Neurosci. 2013, 123, 626-635. [CrossRef]

26. Capurso, C.; Solfrizzi, V.; Colacicco, A.M.; D’Introno, A.; Frisardi, V.; Imbimbo, B.P.; Lorusso, M.; Vendemiale, G.; Denitto, M.; Santamato, A.; et al. Interleukin 6-174 G/C promoter and variable number of tandem repeats (VNTR) gene polymorphisms in sporadic Alzheimer's disease. Prog. Neuropsychopharmacol. Biol. Psychiatry 2010, 34, 177-182. [CrossRef] 
27. Shao, W.; Peng, D.; Wang, X. Genetics of Alzheimer's disease: From pathogenesis to clinical usage. J. Clin. Neurosci. 2017, 45, 1-8. [CrossRef]

28. McKhann, G.; Drachman, D.; Folstein, M.; Katzman, R.; Price, D.; Stadlan, E.M. Clinical diagnosis of Alzheimer's disease: Report of the NINCDS-ADRDA Work Group under the auspices of Department of Health and Human Services Task Force on Alzheimer's Disease. Neurology 1984, 34, 939-944. [CrossRef]

29. Folstein, M.F.; Folstein, S.E.; McHugh, P.R. "Mini-mental state”. A practical method for grading the cognitive state of patients for the clinician. J. Psychiatr. Res. 1975, 12, 189-198. [CrossRef]

30. Blessed, G.; Tomlinson, B.E.; Roth, M. The association between quantitative measures of dementia and of senile change in the cerebral grey matter of elderly subjects. Br. J. Psychiatry 1968, 114, 797-811. [CrossRef]

31. Kato, T.; Honda, M.; Kuwata, S.; Juji, T.; Kunugi, H.; Nanko, S.; Fukuda, M.; Honda, Y. Novel polymorphism in the promoter region of the tumor necrosis factor alpha gene: No association with narcolepsy. Am. J. Med. Genet. 1999, 88, 301-304. [CrossRef]

32. Gnjec, A.; D'Costa, K.J.; Laws, S.M.; Hedley, R.; Balakrishnan, K.; Taddei, K.; Martins, G.; Paton, A.; Verdile, G.; Gandy, S.E.; et al. Association of alleles carried at TNFA -850 and BAT1 -22 with Alzheimer's disease. J. Neuroinflamm. 2008, 5, 36. [CrossRef] [PubMed]

33. Ensembl Genome Browser 98. Available online: http://www.ensembl.org/Homo_sapiens/ Variation/Population?db=core;r=7:22726526-22727526; $\mathrm{v}=\mathrm{rs} 1800795 ; \mathrm{vdb}=$ variation; $\mathrm{vf}=415970384$ (accessed on 20 May 2019).

34. Roses, A.D. Apolipoprotein E alleles as risk factors in Alzheimer's disease. Annu. Rev. Med. 1996, 47, 387-400. [CrossRef] [PubMed]

35. Saunders, A.M.; Strittmatter, W.J.; Schmechel, D.; George-Hyslop, P.H.; Pericak-Vance, M.A.; Joo, S.H.; Rosi, B.L.; Gusella, J.F.; Crapper-MacLachlan, D.R.; Alberts, M.J.; et al. Association of apolipoprotein E allele epsilon 4 with late-onset familial and sporadic Alzheimer's disease. Neurology 1993, 43, 1467-1472. [CrossRef]

36. Corder, E.H.; Saunders, A.M.; Strittmatter, W.J.; Schmechel, D.E.; Gaskell, P.C.; Small, G.W.; Roses, A.D.; Haines, J.L.; Pericak-Vance, M.A. Gene dose of apolipoprotein E type 4 allele and the risk of Alzheimer's disease in late onset families. Science 1993, 261, 921-923. [CrossRef]

37. Neu, S.C.; Pa, J.; Kukull, W.; Beekly, D.; Kuzma, A.; Gangadharan, P.; Wang, L.S.; Romero, K.; Arneric, S.P.; Redolfi, A.; et al. Apolipoprotein E Genotype and Sex Risk Factors for Alzheimer Disease: A Meta-analysis. JAMA Neurol. 2017, 74, 1178-1189. [CrossRef]

38. Panza, F.; Solfrizzi, V.; Torres, F.; Mastroianni, F.; Colacicco, A.M.; Basile, A.M.; Capurso, C.; D’Introno, A.; Del Parigi, A.; Capurso, A. Apolipoprotein E in Southern Italy: Protective effect of epsilon 2 allele in earlyand late-onset sporadic Alzheimer's disease. Neurosci. Lett. 2000, 292, 79-82. [CrossRef]

39. Chen, J.; Shu, H.; Wang, Z.; Liu, D.; Shi, Y.; Xu, L.; Zhang, Z. Protective effect of APOE epsilon 2 on intrinsic functional connectivity of the entorhinal cortex is associated with better episodic memory in elderly individuals with risk factors for Alzheimer's disease. Oncotarget 2016, 7, 58789-58801. [CrossRef]

40. Terreni, L.; Fogliarino, S.; Quadri, P.; Ruggieri, R.M.; Piccoli, F.; Tettamanti, M.; Lucca, U.; Forloni, G. Tumor necrosis factor alpha polymorphism C-850T is not associated with Alzheimer's disease and vascular dementia in an Italian population. Neurosci. Lett. 2003, 344, 135-137. [CrossRef]

41. Dong, X.; Zhang, L.; Meng, Q.; Gao, Q. Association Between Interleukin-1A, Interleukin-1B, and Bridging integrator 1 Polymorphisms and Alzheimer's Disease: A standard and Cumulative Meta-analysis. Mol. Neurobiol. 2017, 54, 736-747. [CrossRef]

42. Kuo, Y.M.; Liao, P.C.; Lin, C.; Wu, C.W.; Huang, H.M.; Lin, C.C.; Chuo, L.J. Lack of association between interleukin-1alpha polymorphism and Alzheimer disease or vascular dementia. Alzheimer Dis. Assoc. Disord. 2003, 17, 94-97. [CrossRef] [PubMed]

43. Fidani, L.; Goulas, A.; Mirtsou, V.; Petersen, R.C.; Tangalos, E.; Crook, R.; Hardy, J. Interleukin-1A polymorphism is not associated with late onset Alzheimer's disease. Neurosci. Lett. 2002, 323, 81-83. [CrossRef]

44. Green, E.K.; Harris, J.M.; Lemmon, H.; Lambert, J.C.; Chartier-Harlin, M.C.; St Clair, D.; Mann, D.M.; Iwatsubo, T.; Lendon, C.L. Are interleukin-1 gene polymorphisms risk factors or disease modifiers in AD? Neurology 2002, 58, 1566-1568. [CrossRef] [PubMed]

45. Rebeck, G.W. Confirmation of the genetic association of interleukin-1A with early onset sporadic Alzheimer's disease. Neurosci. Lett. 2000, 293, 75-77. [CrossRef] 
46. Shawkatová, I.; Javor, J.; Párnická, Z.; Vrazda, L.; Novák, M.; Buc, M. No association between cytokine gene polymorphism and risk of Alzheimer's disease in Slovaks. Acta Neurobiol. Exp. 2010, 70, 303-307.

47. Licastro, F.; Grimaldi, L.M.; Bonafè, M.; Martina, C.; Olivieri, F.; Cavallone, L.; Giovanietti, S.; Masliah, E.; Franceschi, C. Interleukin-6 gene alleles affect the risk of Alzheimer's disease and levels of the cytokine in blood and brain. Neurobiol. Aging 2003, 24, 921-926. [CrossRef]

48. Nishimura, M.; Sakamoto, T.; Kaji, R.; Kawakami, H. Influence of polymorphisms in the genes for cytokines and glutathione S-transferase omega on sporadic Alzheimer's disease. Neurosci. Lett. 2004, 368, 140-143. [CrossRef]

49. Licastro, F.; Porcellini, E.; Caruso, C.; Lio, D.; Corder, E.H. Genetic risk profiles for Alzheimer's disease: Integration of APOE genotype and variants that up-regulate inflammation. Neurobiol. Aging 2007, 28, 1637-1643. [CrossRef]

50. Gilsanz, P.; Quesenberry, C.P., Jr.; Mayeda, E.R.; Glymour, M.M.; Farias, S.T.; Whitmer, R.A. Stressors in Midlife and Risk of Dementia: The Role of Race and Education. Alzheimer Dis. Assoc. Disord. 2019, 33, 200-205. [CrossRef]

51. Kivipelto, M.; Mangialasche, F.; Ngandu, T. Lifestyle interventions to prevent cognitive impairment, dementia and Alzheimer disease. Nat. Rev. Neurol. 2018, 14, 653-666. [CrossRef]

52. Gonzales, M.M.; Tarumi, T.; Eagan, D.E.; Tanaka, H.; Vaghasia, M.; Haley, A.P. Indirect effects of elevated body mass index on memory performance through altered cerebral metabolite concentrations. Psychosom. Med. 2012, 74, 691-698. [CrossRef] [PubMed]

53. Kharabian Masouleh, S.; Arélin, K.; Horstmann, A.; Lampe, L.; Kipping, J.A.; Luck, T.; Riedel-Heller, S.G.; Schroeter, M.L.; Stumvoll, M.; Villringer, A.; et al. Higher body mass index in older adults is associated with lower gray matter volume: Implications for memory performance. Neurobiol. Aging 2016, 40, 1-10. [CrossRef] [PubMed]

54. Kivimäki, M.; Luukkonen, R.; Batty, G.D.; Ferrie, J.E.; Pentti, J.; Nyberg, S.T.; Shipley, M.J.; Alfredsson, L.; Fransson, E.I.; Goldberg, M.; et al. Body mass index and risk of dementia: Analysis of individual-level data from 1.3 million individuals. Alzheimers Dement. 2018, 14, 601-609. [CrossRef] [PubMed] 